\title{
Exploring patient willingness to accept hepatitis C-infected kidneys for transplantation
}

\author{
Gretchen C. Edwards ${ }^{1 *} \mathbb{D}$, Maren E. Shipe ${ }^{1}$, Lindsay Smith², Christianna Gamble², David Shaffer ${ }^{3}$, \\ Beatrice P. Concepcion ${ }^{4}$ and Rachel Forbes ${ }^{3}$
}

\begin{abstract}
Background: As organs infected with Hepatitis C virus ( $\mathrm{HCV}$ ) provide an opportunity to expand the donor pool, the primary aim of this study is to explore patient willingness to accept a kidney from HCV-infected donors compared to other high-risk donors.
\end{abstract}

Methods: An anonymous, electronic survey was sent to all active kidney transplant waitlist patients at a single large volume transplant center. Patients were asked to respond to three hypothetical organ offers from the following: 1) HCV-infected donor 2) Donor with active intravenous drug use and 3) Donor with longstanding diabetes and hypertension.

Results: The survey was sent to 435 patients of which 125 responded (29\% response rate). While 86 out of 125 patients (69\%) were willing to accept an HCV-infected kidney, only a minority of respondents were willing to accept a kidney from other high-risk donors. In contrast to other studies, by multivariable logistic regression, age and race were not associated with willingness to accept an HCV-infected kidney.

Conclusions: In this exploratory study, utilization of kidneys from HCV-infected donors to expand the donor pool appears to be an acceptable option to patients.

Keywords: Hepatitis C, PHS-high risk, Expanded donor criteria, Deceased donor kidney transplant, Disparities

\section{Background}

There is a critical shortage of donor organs for patients awaiting kidney transplantation. According to the Organ Procurement and Transplantation Network (OPTN), nearly 100,000 patients remain on the kidney transplant waiting list in the United States (U.S.) and yet only 10, 000 patients underwent deceased donor kidney transplantation in 2018 [1]. As the demand for organs continues to outpace supply and waiting times exceed up to

\footnotetext{
* Correspondence: Gretchen.C.Edwards@vumc.org

'Department of General Surgery, Vanderbilt University Medical Center,

Medical Center North, Suite CCC-4312, 1161 21st Avenue South, Nashville, TN 37232-2730, USA

Full list of author information is available at the end of the article
}

5 years in many parts of the country, multiple approaches are now being considered to safely expand the donor pool [2]. These include donation after circulatory death, public health service (PHS) increased risk donors, older donors with comorbidities, and those previously exposed to or infected with hepatitis C (HCV).

The ongoing opioid epidemic in the U.S. has resulted in a dramatic increase in the number of deaths due to overdose with intravenous drug use (IVDU), leading to a significant increase in donors classified as PHS increased risk and those infected with $\mathrm{HCV}$ [3]. With the advent of direct-acting antiviral agents (DAA) for the treatment of $\mathrm{HCV}$, there has been great interest in the potential to increase the donor pool by offering waitlisted patients

C C The Author(s). 2020 Open Access This article is licensed under a Creative Commons Attribution 4.0 International License, which permits use, sharing, adaptation, distribution and reproduction in any medium or format, as long as you give appropriate credit to the original author(s) and the source, provide a link to the Creative Commons licence, and indicate if changes were made. The images or other third party material in this article are included in the article's Creative Commons licence, unless indicated otherwise in a credit line to the material. If material is not included in the article's Creative Commons licence and your intended use is not permitted by statutory regulation or exceeds the permitted use, you will need to obtain permission directly from the copyright holder. To view a copy of this licence, visit http://creativecommons.org/licenses/by/4.0/ The Creative Commons Public Domain Dedication waiver (http://creativecommons.org/publicdomain/zero/1.0/) applies to the data made available in this article, unless otherwise stated in a credit line to the data. 
HCV-infected kidneys. The cure rates of various DAA regimens exceed $90 \%$ in the general population and evidence is growing to suggest that similarly high cure rates can be achieved among immunosuppressed recipients and those with renal dysfunction [4-8]. Notably, two independent single-center pilot studies demonstrated $100 \%$ cure rates and excellent outcomes in a total of 30 uninfected patients who received HCV-infected kidneys and were subsequently treated with DAA posttransplant $[9,10]$. More recently, others have reported excellent outcomes on this practice when performed as standard of care, i.e. outside of a clinical trial [11, 12].

Despite the growing interest in the transplant community to broadly adopt the practice of transplanting $\mathrm{HCV}$ infected kidneys into uninfected recipients, little is known about patient willingness to accept such kidneys and how this compares to willingness to accept other "non-standard" kidneys such as PHS increased risk and high kidney donor profile index (KDPI).

The aims of this study were: First, to quantify patient willingness to receive a kidney from a donor with HCVviremia; second, to compare this with willingness to accept a kidney from a representative PHS increased risk or marginal (high KDPI) donor; and third, to identify clinical characteristics associated with willingness to accept an HCV-infected kidney.

\section{Methods}

\section{Participants and survey administration}

An anonymous, electronic survey was administered to all active kidney transplant waitlist patients with a registered email address at a large volume transplant center in Nashville, TN as part of an exploratory initiative to gauge interest among waitlisted patients in accepting HCV-infected kidneys. As such, no pilot survey was conducted at the initiation of the study. However, all study materials were reviewed by transplant center staff who regularly produce educational and survey materials for this study population. Multiple iterations were circulated among transplant center including surgery, nephrology, nursing, and administrative staff. Furthermore, the survey was set up in a similar fashion to the hypothetical situations posed by McCauley, et al., whose work was based on semi-structured interviews [13]. Survey data were collected via the REDCap electronic data capture tool. Patients were provided introductory information to the survey, including observed $\mathrm{HCV}$ cure rates with current DAA therapy, and were informed that participation was completely voluntary. All patients had previously undergone in-person pre-transplant education at the transplant center which included education regarding the risks and benefits of PHS-increased risk and high KDPI kidneys, but not HCV-infected kidneys. This study was deemed exempt under the Institutional Review Board (IRB \# 190290).

\section{Demographic and clinical data}

Patients were asked for demographic information (age, sex, race, ethnicity, education level), waitlist time, dialysis time, type of dialysis, and history of a prior kidney transplant. Patients were also asked if they had been diagnosed and/or treated for HCV and if they had any personal contacts with known history of HCV. They were then asked to respond to three hypothetical kidney offers as follows: 1) 20-year-old HCV-infected donor with a greater than $95 \%$ chance of successful HCV cure following transplant; 2) 20-year-old PHS-increased risk donor with active IVDU at time of death; and 3) 70year-old donor with long-standing hypertension and diabetes. For those patients who reported "no" to any organ offer, they were then asked to indicate how much additional time they would be willing to remain on the transplant list in order to receive a "standard" kidney offer. Finally, patients were asked if added costs or doctor visits for $\mathrm{HCV}$ treatment were of concern to them. A full copy of the survey is included as Additional file 1 .

\section{Statistical analysis}

This study was designed as an exploratory survey to gauge attitudes regarding willingness to accept HCVpositive organs and to shape further educational and outreach efforts regarding these organ offers. Thus, no sample size calculation was performed. Descriptive analysis including mean and median for continuous variables and frequencies for categorical variables were calculated. Student $t$ test and one-way analysis of variance (continuous variables) and Fisher's exact test (categorical data) were used to compare differences between groups. Multivariable logistic regression was utilized to identify clinical characteristics which were independently associated with willingness to accept an $\mathrm{HCV}$-infected kidney. Covariates included in the model were chosen a priori and included age, race, gender, educational status, and time on dialysis. Time on dialysis was categorized to "less than 2 years" and "greater than or equal to 2 years" while educational status was categorized as "some college or less" and "graduated college, graduate or doctoral degree". All analyses were performed using Stata 15.1 (StataCorp, College Station, TX).

\section{Results}

A total of 435 patients who were actively listed for kidney transplant at our center and had a registered email address were sent the electronic link to the REDCap survey. There were 125 patients who responded (29\% response rate). The demographic and clinical characteristics of the cohort are presented in Table 1. The 
Table 1 Demographic and clinical characteristics of survey participants $(n=125)$

\begin{tabular}{|c|c|c|c|c|}
\hline & Overall & $\begin{array}{l}\text { Unwilling to receive HCV+ kidney } \\
(N=39)\end{array}$ & $\begin{array}{l}\text { Willing to receive } \mathrm{HCV}+\text { kidney } \\
(N=86)\end{array}$ & $P$-value \\
\hline Mean age (years) +/- SD & $55+/-1.06$ & $51+/-2.3$ & $56.7+/-1.1$ & 0.012 \\
\hline Male sex, N (\%) & $71(56.8)$ & $20(51.3)$ & $51(59.3)$ & 0.402 \\
\hline \multicolumn{5}{|l|}{ Race } \\
\hline White, N (\%) & $82(65.6)$ & $25(64.1)$ & $57(66.3)$ & \\
\hline Black, N (\%) & $35(28.0)$ & $11(28.2)$ & $24(27.9)$ & \\
\hline Other, N (\%) & $8(6.4)$ & $3(7.7)$ & $5(5.8)$ & 0.919 \\
\hline Currently on dialysis, N (\%) & $88(70.4)$ & $30(77.0)$ & $58(67.4)$ & 0.282 \\
\hline Two or more years on dialysis, N (\%) & $44(35.2)$ & $11(28.2)$ & $33(22.1)$ & 0.072 \\
\hline \multicolumn{5}{|l|}{ Dialysis type, N (\%) } \\
\hline Hemodialysis & $58(65.9)$ & $19(48.7)$ & $39(45.3)$ & \\
\hline Peritoneal dialysis & $30(34.1)$ & $11(28.2)$ & $19(22.1)$ & 0.174 \\
\hline Mean number of years listed, +/- SD & $1.9+/-0.15$ & $1.9+/-0.27$ & $2.0+/-0.18$ & 0.66 \\
\hline History of prior kidney transplant, N (\%) & $19(15.2)$ & $8(20.5)$ & $11(12.8)$ & 0.265 \\
\hline Personal history of HCV, N (\%) & $6(4.8)$ & $1(2.6)$ & $5(5.8)$ & 0.424 \\
\hline Previously treated for HCV, N (\%) & $6(4.8)$ & $1(2.6)$ & $5(5.8)$ & 0.424 \\
\hline Know someone with HCV, N (\%) & $20(16.0)$ & $7(17.9)$ & $13(15.1)$ & 0.689 \\
\hline \multicolumn{5}{|l|}{ Educational level, N (\%) } \\
\hline Some high school & $4(3.2)$ & $0(0)$ & $4(4.7)$ & \\
\hline High school diploma or GED & $19(15.2)$ & $4(10.3)$ & $15(17.4)$ & \\
\hline Some college & $43(34.4)$ & $13(33.3)$ & $30(34.9)$ & \\
\hline Graduated college & $37(29.6)$ & $10(25.6)$ & $27(31.4)$ & \\
\hline Graduate or doctoral degree & $22(17.6)$ & $12(30.8)$ & $10(11.6)$ & 0.071 \\
\hline $\begin{array}{l}\text { Interested in hearing more about } \\
\text { HCV-positive organs }\end{array}$ & $75(60.0)$ & $5(12.8)$ & $70(81.4)$ & $<0.001$ \\
\hline
\end{tabular}

mean age was 55 years, $57 \%$ were male, $66 \%$ were white, and $28 \%$ were black. Of the patients who responded, $70 \%$ are currently on dialysis, the majority of whom undergo hemodialysis (66\%). Time on dialysis as well as time on transplant list (years) are also shown in Table 1.

Out of 125 respondents, 86 (69\%) were willing to accept an HCV-infected kidney. In unadjusted analysis, those patients willing to receive $\mathrm{HCV}$-infected kidneys were significantly older (57 versus 51 years old, $p=$ $0.012)$. There was no significant difference in willingness to accept HCV-infected kidneys by sex, race, time on dialysis, or educational status (Table 1). In contrast to patient willingness to accept an $\mathrm{HCV}$-infected kidney, only a minority of respondents were willing to accept a kidney from a donor with active IVDU at the time of death $(37 \%)$ or from an older donor with long-standing history of diabetes and hypertension (39\%) (Fig. 1).

In multivariable logistic regression analysis, neither age (OR 1.03, 95\% CI 0.99-1.07) nor race (OR 0.63, 95\% CI 0.24-1.68) were significantly associated with willingness to accept HCV-infected kidneys after adjustment for sex, time on dialysis, or educational status. (Table 2).
For those patients who reported "no" to any organ offer and were subsequently asked to respond to how much additional time they would be willing to wait in order to receive a "standard" kidney offer, those who declined an HCV-infected kidney were willing to wait for a mean additional time of 3.5 years. Finally, 38\% of patients were concerned about the additional costs of HCV medications as well as the burden of additional office visits for HCV treatment.

\section{Discussion}

In an exploratory survey conducted in a large volume transplant center in the Southeastern United States, we found that most patients were willing to accept an offer for an HCV-infected kidney. In contrast to prior studies, our data suggest that there were no significant differences in willingness to accept offers for HCV-infected kidneys based on age and race. Our finding that majority of patients are interested in accepting an HCV-infected kidney is similar to what other groups who have found in their own patient population. However, in contrast to our findings, these studies found that older patients and 


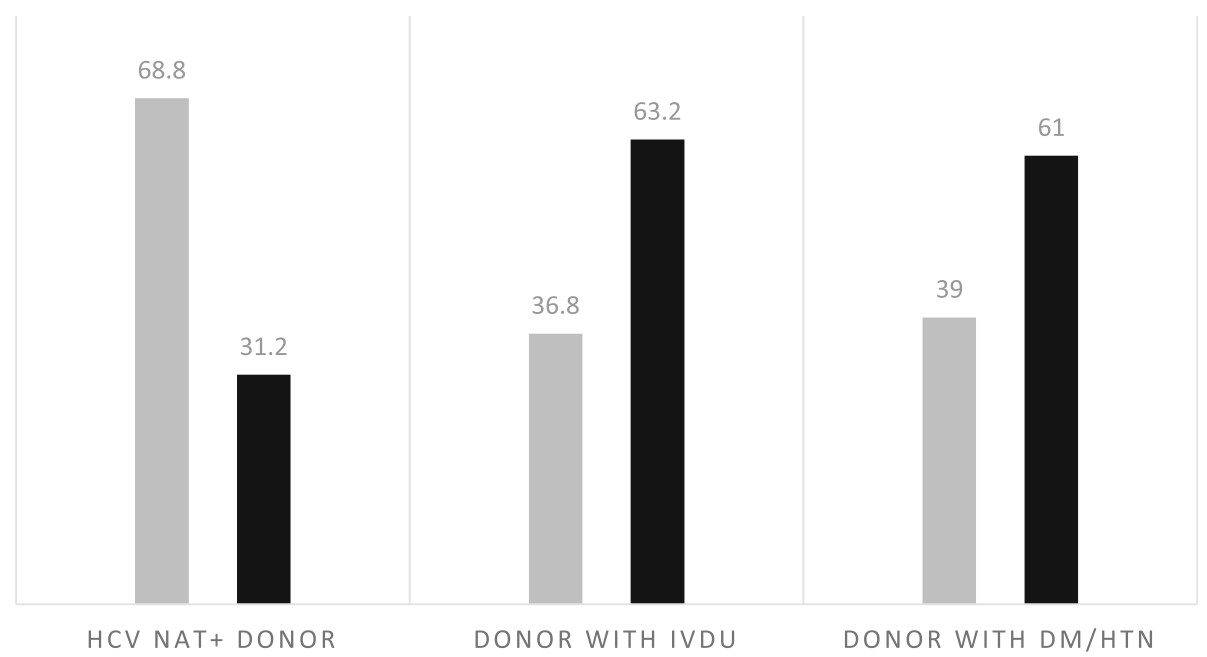

Fig. 1 Willingness (\%) to accept three hypothetical organ offers: 1) 20-year old HCV NAT+ donor, 2) 20-year-old donor with IVDU at time of death, or 3) 70-year old donor with long-standing diabetes and hypertension

white patients were more willing to accept HCVinfected kidneys than younger and black patients, respectively $[13,14]$. The reason for the contrast in the results is unclear but may represent unmeasured differences in each transplant center's characteristics and patient population.

While our study demonstrates that many patients are open to HCV-infected kidneys once educated regarding the safety and efficacy of DAA therapy post-transplant, they also suggest that other types of "high-risk" donation is less clear to patients. The majority of our respondents were unwilling to receive an organ from a donor with active IVDU at the time of death, albeit with negative HIV and HCV serologies. Similarly, the majority of our respondents were unwilling to receive an organ from an older donor with diabetes and hypertension, two disease states contributing to end-stage renal disease. In these scenarios, there may be an element of uncertainty regarding expected outcome for both the patient and the provider.

This lack of certainty is clearly problematic, as the designation of PHS-increased risk leads to non-utilization of hundreds of organs every year [15]. In focus groups, Ros, et al. found that patients desired additional information about PHS-increased risk donors, including behaviors, kidney quality, and probability of undetected infection. This study also found that patients heavily weighed the opinion of their transplant provider in making recommendations regarding organ offers [16].

Participants in our survey received a modest amount of educational material regarding $\mathrm{HCV}$-infected kidney offers and treatment prior to completing this anonymous survey. Given these data and other groups' findings that patients prominently consider the opinion of the transplant provider in whether or not to accept an organ offer, we suggest that providers carefully consider the risks and benefits of an organ offer with their patients. These discussions should include consideration of patient age, current quality of life, and ability to detect and treat potentially transmitted infections.

This study has several limitations. First, our response rate was low (29\%), participation was voluntary, and the sample size was limited. In order to more fully validate our results, a larger study cohort will be necessary. Therefore, it is possible that our findings are influenced by non-response bias and that patients who are interested in $\mathrm{HCV}$-infected kidneys would be more likely to respond to this survey. Second, all respondents are listed

Table 2 Multivariable logistic regression model for willingness to accept an HCV-infected kidney

\begin{tabular}{|c|c|c|c|}
\hline Question: Willing to receive organ from HCV NAT+ donor & Odds Ratio & $95 \% \mathrm{Cl}$ & $P$-value \\
\hline Age & 1.03 & $0.99-1.07$ & 0.13 \\
\hline Sex (Ref: Male) & 0.84 & $0.31-2.27$ & 0.74 \\
\hline Race (Ref: White) & 0.63 & $0.24-1.68$ & 0.36 \\
\hline$\geq 2$ years on dialysis (Ref: $<2$ years on dialysis) & 2.08 & $0.79-5.52$ & 0.14 \\
\hline Educational status college or graduate degree (Ref: Some college or less) & 0.42 & $0.16-1.11$ & 0.08 \\
\hline
\end{tabular}


at a single academic institution, which may limit the generalizability of the study. Third, the survey was designed to primarily gauge interest in accepting HCVinfected kidneys, hence no additional education within the survey was provided regarding the risks and benefits of accepting a PHS-increased risk or high KDPI kidney. While patients did receive in-person education regarding these kidneys during their evaluation at our transplant center, an important future direction of the study includes providing more focused educational material to respondents regarding each type of organ offer. Additionally, a full qualitative evaluation of the study questions within a pilot group before expanding to a larger cohort will be an important additional step in validating these findings. Finally, due to the limited number of events and to avoid overfitting the model, some other potential confounders may not have been included in the multivariable analysis.

\section{Conclusions}

This exploratory study suggests that patients currently on the waitlist for kidney transplant are willing to consider organ offers from HCV-infected kidneys, but may be less accepting of organ offers from other "high-risk" donors without additional education and information about such offers. While the results of this initial survey are limited, these results suggest a need for each transplant center to survey their own transplant population. In order to validate the results of this preliminary work, qualitative validation of the study questions and a larger study cohort will be necessary. Equipping patients and providers alike with more tools to navigate decisionmaking regarding higher-risk donors remains an area of ongoing research.

\section{Supplementary Information}

The online version contains supplementary material available at https://doi. org/10.1186/s12882-020-02114-y.

Additional file 1.

\section{Abbreviations}

HCV: Hepatitis C Virus; PHS: Public Health Service; OPTN: Organ Procurement and Transplantation Network; IVDU: Intravenous drug use; DAA: Direct-acting antiviral agents; KDPI: Kidney donor profile index

\section{Acknowledgments}

Not applicable.

\section{Authors' contributions}

$\mathrm{GE}, \mathrm{RF}, \mathrm{BC}$ were responsible for the study concepts, survey design, and implementation. LS and CG assisted with survey design and distribution. GE and MS analyzed and interpreted the data. RF, DS, MS, and BC provided editorial support. All authors read and approved the final manuscript.

\section{Funding}

Dr. Edwards is supported by the VA Quality Scholars Program, VA Geriatric Research Education \& Clinical Center (GRECC).
Dr. Shipe is supported by the Agency for Healthcare Research (AHRQ) under Award Number T32 HS026122.

These funders provided salary support to Drs. Edwards and Shipe.

\section{Availability of data and materials}

The datasets used and/or analyzed during the current study are available from the corresponding author on reasonable request.

\section{Ethics approval and consent to participate}

This study was submitted and deemed exempt under the Vanderbilt University Medical Center Institutional Review Board (IRB \# 190290). The survey was anonymous and voluntary on the part of the participants, and thus need for consent was waived by the afore-mentioned IRB. Need for additional ethics approval was waived by the IRB.

Consent for publication

Not applicable.

\section{Competing interests}

The authors declare that they have no competing interests.

\section{Author details}

${ }^{1}$ Department of General Surgery, Vanderbilt University Medical Center, Medical Center North, Suite CCC-4312, 1161 21st Avenue South, Nashville, TN 37232-2730, USA. ² Vanderbilt University Medical Center Transplant Center, Nashville, USA. ${ }^{3}$ Department of General Surgery, Division of Kidney and Pancreas Transplantation, Vanderbilt University Medical Center, Nashville, USA. ${ }^{4}$ Department of Medicine, Division of Nephrology and Hypertension, Vanderbilt University Medical Center, Nashville, USA.

Received: 20 November 2019 Accepted: 20 October 2020

Published online: 10 November 2020

\section{References}

1. "National Data - OPTN." n.d. Accessed 22 Jan 2019. https://optn.transplant. hrsa.gov/data/view-data-reports/national-data/.

2. Kling CE, Limaye AP, Landis CS, Sibulesky L. Expanding access to transplantation with hepatitis C-positive donors: a new perspective on an old issue. Clin Transpl. 2017;31(2). https://doi.org/10.1111/ctr.12884.

3. Volk ML, Wilk AR, Wolfe C, Kaul DR. The 'PHS increased risk' label is associated with nonutilization of hundreds of organs per year. Transplantation. 2017;101(7):1666-9.

4. Goldberg DS, Abt PL, Blumberg EA, Van Deerlin VM, Levine M, Rajender Reddy K, Bloom RD, et al. Trial of transplantation of HCV-infected kidneys into uninfected recipients. N Engl J Med. 2017;376(24):2394-5.

5. Schlendorf KH, Zalawadiya S, Shah AS, Wigger M, Chung CY, Smith S, Danter $M$, et al. Early outcomes using hepatitis C-positive donors for cardiac transplantation in the era of effective direct-acting anti-viral therapies. J Heart Lung Transpl. 2018;37(6):763-9.

6. Roth D, Nelson DR, Bruchfeld A, Liapakis A, Silva M, Monsour H Jr, Martin P, et al. Grazoprevir plus Elbasvir in treatment-naive and treatmentexperienced patients with hepatitis C virus genotype 1 infection and stage 4-5 chronic kidney disease (the C-SURFER study): a combination phase 3 study. Lancet. 2015;386(10003):1537-45.

7. Naganuma A, Chayama K, Notsumata K, Gane E, Foster GR, Wyles D, Kwo P, et al. Integrated analysis of 8-week Glecaprevir/pibrentasvir in Japanese and overseas patients without cirrhosis and with hepatitis $C$ virus genotype 1 or 2 Infection. J Gastroenterology. 2019. https://doi.org/10.1007/s00535-01901569-7.

8. Reau N, Kwo PY, Rhee S, Brown RS Jr, Agarwal K, Angus P, Gane E, et al. Glecaprevir/Pibrentasvir treatment in liver or kidney transplant patients with hepatitis C virus infection. Hepatology. 2018;68(4):1298-307.

9. Reese PP, Abt PL, Blumberg EA, Van Deerlin VM, Bloom RD, Potluri VS, Levine $M$, et al. Twelve-month outcomes after transplant of hepatitis Cinfected kidneys into uninfected recipients: a single-group trial. Ann Intern Med. 2018;169(5):273-81.

10. Durand CM, Bowring MG, Brown DM, Chattergoon MA, Massaccesi G, Bair $\mathrm{N}$, Wesson $\mathrm{R}$, et al. Direct-acting antiviral prophylaxis in kidney transplantation from hepatitis C virus-infected donors to noninfected recipients: an open-label nonrandomized trial. Ann Intern Med. 2018;168(8): 533-40. 
11. Molnar MZ, et al. Transplantation of kidneys from hepatitis C-infected donors to hepatitis C-negative recipients: single center experience. Am J Transplant. 2019. https://doi.org/10.1111/ajt.15530.

12. Kapila N, et al. HCV NAT positive solid organ allografts transplanted into HCV negative recipients: a real-world experience. Hepatology. 2019. https://doi.org/10.1002/hep.31011.

13. McCauley M, Mussell A, Goldberg D, Sawinski D, Molina RN, Tomlin R, Doshi $\mathrm{SD}$, et al. Race, risk, and willingness of end-stage renal disease patients without hepatitis C virus to accept an HCV-infected kidney transplant. Transplantation. 2018;102(4):e163-70.

14. Couri T, Cotter TG, Chen D, Hammes M, Reddy B, Josephson M, Yeh H, Chung RT, Paul S. Use of hepatitis C positive organs: patient attitudes in urban Chicago. Am J Nephrol. 2019;49(1):32-40.

15. Pruett TL, Clark MA, Taranto SE. Deceased organ donors and PHS risk identification: impact on organ usage and outcomes. Transplantation. 2017; 101(7):1670-8

16. Ros RL, Kucirka LM, Govindan P, Sarathy H, Montgomery RA, Segev DL. Patient attitudes toward CDC high infectious risk donor kidney transplantation: inferences from focus groups. Clin Transpl. 2012;26(2):247-53.

\section{Publisher's Note}

Springer Nature remains neutral with regard to jurisdictional claims in published maps and institutional affiliations.

Ready to submit your research? Choose BMC and benefit from:

- fast, convenient online submission

- thorough peer review by experienced researchers in your field

- rapid publication on acceptance

- support for research data, including large and complex data types

- gold Open Access which fosters wider collaboration and increased citations

- maximum visibility for your research: over $100 \mathrm{M}$ website views per year

At BMC, research is always in progress.

Learn more biomedcentral.com/submissions 